\title{
tmRNA-mediated trans-translation as the major ribosome rescue system in a bacterial cell
}

\section{Hyouta Himeno*, Daisuke Kurita and Akira Muto}

Department of Biochemistry and Molecular Biology, Faculty of Agriculture and Life Science, Hirosaki University, Hirosaki, Japan

\section{Edited by:}

Akio Kanai, Keio University, Japan

Reviewed by:

Toshifumi Inada, Tohoku University, Japan

Yoshitaka Bessho, RIKEN SPring-8

Center, Japan

\section{*Correspondence:}

Hyouta Himeno, Department of

Biochemistry and Molecular Biology,

Faculty of Agriculture and Life

Science, Hirosaki University,

Hirosaki 036-8561, Japan

email: himeno@cc.hirosaki-u.ac.jp
Transfer messenger RNA (tmRNA; also known as 10Sa RNA or SsrA RNA) is a small RNA molecule that is conserved among bacteria. It has structural and functional similarities to tRNA: it has an upper half of the tRNA-like structure, its $5^{\prime}$ end is processed by RNase $P$, it has typical tRNA-specific base modifications, it is aminoacylated with alanine, it binds to EF-Tu after aminoacylation and it enters the ribosome with EF-Tu and GTP. However, tmRNA lacks an anticodon, and instead it has a coding sequence for a short peptide called tagpeptide. An elaborate interplay of actions of tmRNA as both tRNA and mRNA with the help of a tmRNA-binding protein, $\mathrm{SmpB}$, facilitates trans-translation, which produces a single polypeptide from two mRNA molecules. Initially alanyl-tmRNA in complex with EF-Tu and SmpB enters the vacant A-site of the stalled ribosome like aminoacyl-tRNA but without a codon-anticodon interaction, and subsequently truncated mRNA is replaced with the tag-encoding region of tmRNA. During these processes, not only tmRNA but also SmpB structurally and functionally mimics both tRNA and mRNA. Thus trans-translation rescues the stalled ribosome, thereby allowing recycling of the ribosome. Since the tag-peptide serves as a target of $\mathrm{AAA}^{+}$proteases, the trans-translation products are preferentially degraded so that they do not accumulate in the cell. Although alternative rescue systems have recently been revealed, trans-translation is the only system that universally exists in bacteria. Furthermore, it is unique in that it employs a small RNA and that it prevents accumulation of non-functional proteins from truncated mRNA in the cell. It might play the major role in rescuing the stalled translation in the bacterial cell.

Keywords: tmRNA, SmpB, ribosome, trans-translation, molecular mimicry

\section{INTRODUCTION}

Translation often stalls in various situations in a cell, sometimes in a programmed fashion and other times unexpectedly. For example, translation of mRNA lacking a stop codon (non-stop mRNA) does not terminate efficiently because peptide release factor does not function. Thus, the cell should have a system to cope with such emergencies. However, little attention was given to this issue until the mid-1990s, and therefore the discovery of tmRNA was a big surprise. Initially the tRNA-like structure and function of tmRNA were elucidated. Both terminal regions of tmRNA can form a secondary structure resembling the upper half of the cloverleaf-like structure of tRNA (Komine et al., 1994; Ushida et al., 1994), which includes several tRNA-specific consensus sequences and base modifications (Figure 1A; Felden et al., 1997, 1998). Like that of tRNA, the $3^{\prime}$ end of tmRNA can be aminoacylated with an amino acid (alanine) by an aminoacyltRNA synthestase (alanyl-tRNA synthetase; Komine et al., 1994; Ushida et al., 1994). Other tRNA-like functions, such as $5^{\prime}$ processing by RNase P (Komine etal., 1994), binding to EF-Tu (Rudinger-Thirion et al., 1999; Barends et al., 2000, 2001; HanawaSuetsugu et al., 2001) and interaction with 70S ribosome (Ushida et al., 1994; Komine etal., 1996; Tadaki etal., 1996), have also been revealed. Although it is about fivefold larger than tRNA, tmRNA has no apparent anticodon, making it difficult to clarify whether and how tmRNA is involved in translation. A few years later, it was found that tmRNA has functions not only as tRNA but also as mRNA: a short peptide is encoded by the middle part of tmRNA (Tu et al., 1995), which is surrounded by four pseudoknot structures (Figure 1A; Nameki et al., 1999b,c). Intriguingly, these two functions cooperate, rather than being independent, to produce a chimeric polypeptide from two mRNAs, a C-terminally truncated polypeptide encoded by mRNA fusing the tmRNAencoded short peptide with an alanine residue of unknown origin in between them (Keiler etal., 1996; Muto et al., 1996; Himeno et al., 1997). This acrobatic translation involving co-translational mRNA swapping produces a single polypeptide from two mRNAs, and thus it has been called trans-translation (Figure 2; Muto et al., 1998). This system provides a stop codon to allow completion of translation of a non-stop mRNA and consequently recycling of the ribosome. In addition, trans-translation has been regarded as a quality control system that prevents non-functional polypeptides derived from truncated mRNAs from accumulating in the cell, as the tag-peptide consisting of the first alanine residue and the tmRNA-encoded short peptide, especially the sequence of the last four hydrophobic amino acids (ALAA), serves as the target for cellular ATP-dependent proteases (Gottesman et al., 1998; Herman etal., 1998; Flynn et al., 2001; Choy et al., 2007).

Trans-translation requires a tmRNA binding protein called SmpB in addition to canonical elongation factors (Karzai et al., 


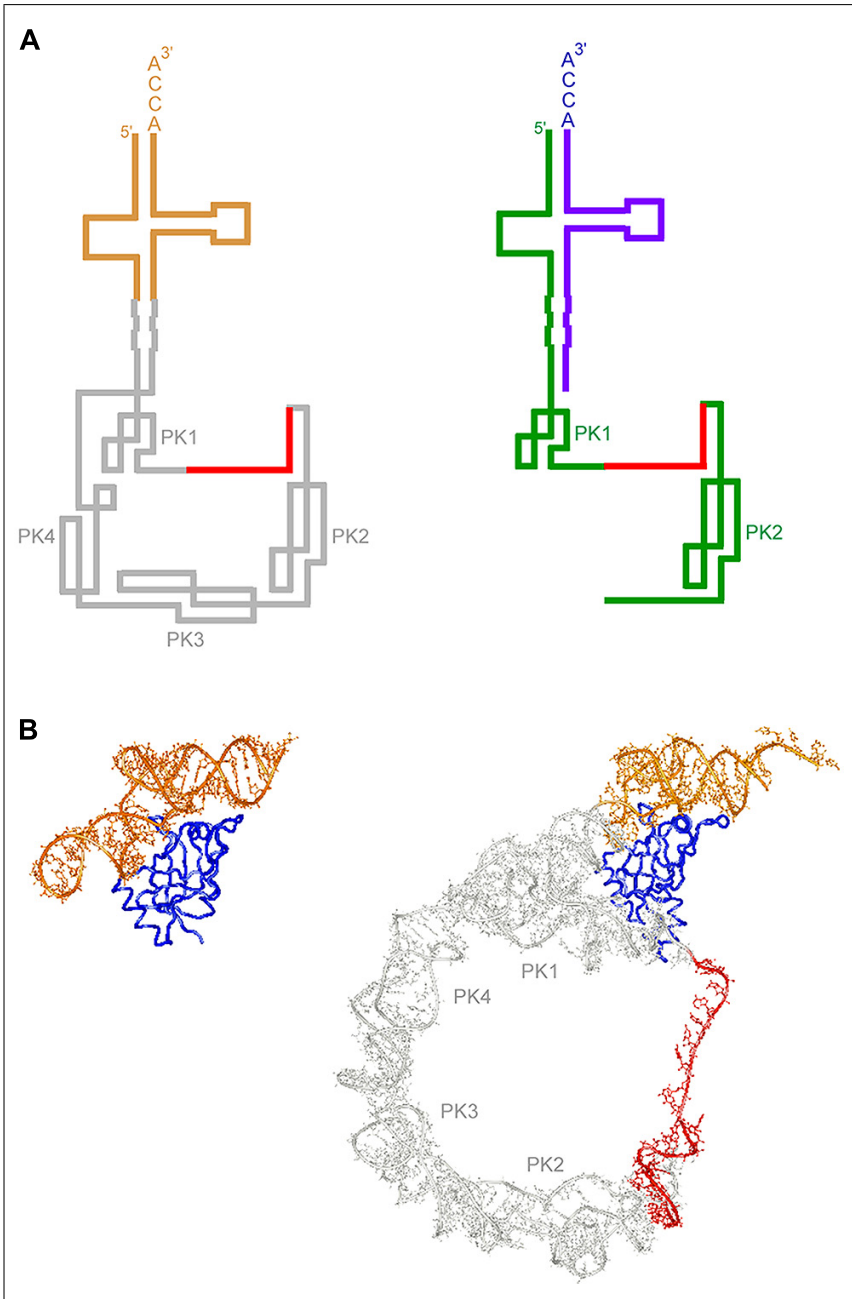

FIGURE 1 | Secondary and tertiary structures of tmRNA. (A) Secondary structure of tmRNA. (Left) The most typical secondary structure of tmRNA is shown, with TLD and the tag-encoding region designated in brown and red, respectively. (Right) A secondary structure of two-piece tmRNA. The $5^{\prime}$-coding piece and $3^{\prime}$-amino acid acceptor piece are designated in green and violet, respectively. (B) Tetiary structure of tmRNA or its fragment in complex with SmpB. (Left) A crystal structure of a complex of a TLD fragment lacking the $3^{\prime} \mathrm{CCA}$ end of $T$. thermophilus tmRNA (the $5^{\prime} 25$ residues and 3' 34 residues connected by a UUCG loop) and the globular domain (N-terminal 123 of a total of 144 residues) of SmpB (PDB ID: 2CZJ; Bessho et al., 2007). TLD (brown) and SmpB (dark blue) mimic the upper and lower halves of the L-shaped structure of tRNA, respectively. (Right) $A$ cryo-EM structure of tmRNA.SmpB in a T. thermophilus post-translocated state complex of trans-translation (PDB ID: 3YIR; Weis et al., 2010b) is shown, with TLD, the tag-encoding region and $\mathrm{SmpB}$ designated in brown, red, and dark blue, respectively. The N-terminal globular domain of SmpB mimicking the lower half of the L-shaped structure of tRNA is in close contact with the upstream region of the tag-encoding sequence.

1999). SmpB consists of a globular domain and an unstructured C-terminal tail (Dong et al., 2002; Someya et al., 2003). It binds to the tRNA-like domain (TLD) of tmRNA to prevent tmRNA from degradation and enhance aminoacylation of tmRNA (Barends et al., 2001; Hanawa-Suetsugu et al., 2002; Shimizu and Ueda, 2002; Nameki et al., 2005). SmpB also plays a crucial role in the ribosomal process of trans-translation.
The trans-translation system is universally present in bacterial cells and is present in organelles of some eukaryotes but not in the cytoplasm of eukaryotes or archaebacteria. There is accumulating evidence indicating that the bacterial cell is equipped with additional systems to cope with stalled translation. Here, we review the current understanding of the molecular mechanism and the cellular functions of tmRNA-mediated trans-translation as well as other ribosome rescue systems.

\section{MOLECULAR MECHANISM OF TRANS-TRANSLATION}

An outline of the process of trans-translation is as follows (Figure 3): initially, tmRNA in complex with $\mathrm{SmpB}$ is aminoacylated with alanine by alanyl-tRNA synthetase. Ala-tmRNA enters the A-site of the stalled ribosome on a truncated mRNA to receive the nascent polypeptide from peptidyl-tRNA in the P-site. Then peptidyl-Ala-tmRNA translocates to the P-site, which exchanges the template from truncated mRNA to the tag-encoding region on tmRNA. It can reasonably explain the missing origin of the alanine residue connecting the truncated polypeptide encoded by mRNA with the tmRNA-encoded tag-peptide: it is derived from the alanine moiety aminoacylated to tmRNA. This model was proposed on the basis of the results of an in vivo study showing that truncated polypeptides fusing the tmRNA-encoding tag-peptide in its C-termini accumulate in the cell when a truncated mRNA is expressed (Keiler et al., 1996), and the model was supported by the results of an in vitro study showing that the tag-peptide is synthesized using Escherichia coli cell extract depending on the addition of poly $(\mathrm{U})$ and on the aminoacylation capacity of tmRNA (Muto et al., 1996; Himeno et al., 1997). However, several questions have been raised. How does tmRNA find the stalled ribosome? How does tmRNA enter the A-site of the ribosome without an anticodon? How does the tag-encoding region of tmRNA substitute for truncated mRNA? How is the resuming point on tmRNA determined? SmpB has emerged as the key molecule to solve these questions.

Besides canonical translation factors and tmRNA, SmpB is the minimal requirement for in vitro trans-translation (Shimizu and Ueda, 2002; Takada et al., 2007; Kurita et al., 2012). SmpB has been thought to continue binding to tmRNA throughout the process of trans-translation (Ivanova et al., 2007). In a crystal structure of a complex of SmpB and a model RNA fragment corresponding to TLD of tmRNA, the globular domain of SmpB binds to TLD so that it compensates for the lack of the lower half of the L-form structure in tmRNA (Figure 1B; Gutmann et al., 2003; Bessho et al., 2007). Thus, TLD in complex with the globular domain of SmpB would structurally mimic a whole tRNA molecule. A directed hydroxyl radical probing study has revealed two SmpB binding sites in an E. coli ribosome, one in the A-site and the other in the P-site, both of which can be superimposed on the lower half of the tRNA molecules in the translating ribosome (Kurita et al., 2007). An additional mimicry of the upper half of tRNA by TLD could complete two whole translating tRNA mimics at the A-site and P-site so that their aminoacyl ends are oriented to the peptidyl-transferase center. The pattern of cleavage of $16 \mathrm{~S}$ rRNA by hydroxyl radicals from the C-terminal tail residues has suggested two binding sites of the Cterminal tail of SmpB with two different modes of conformation 


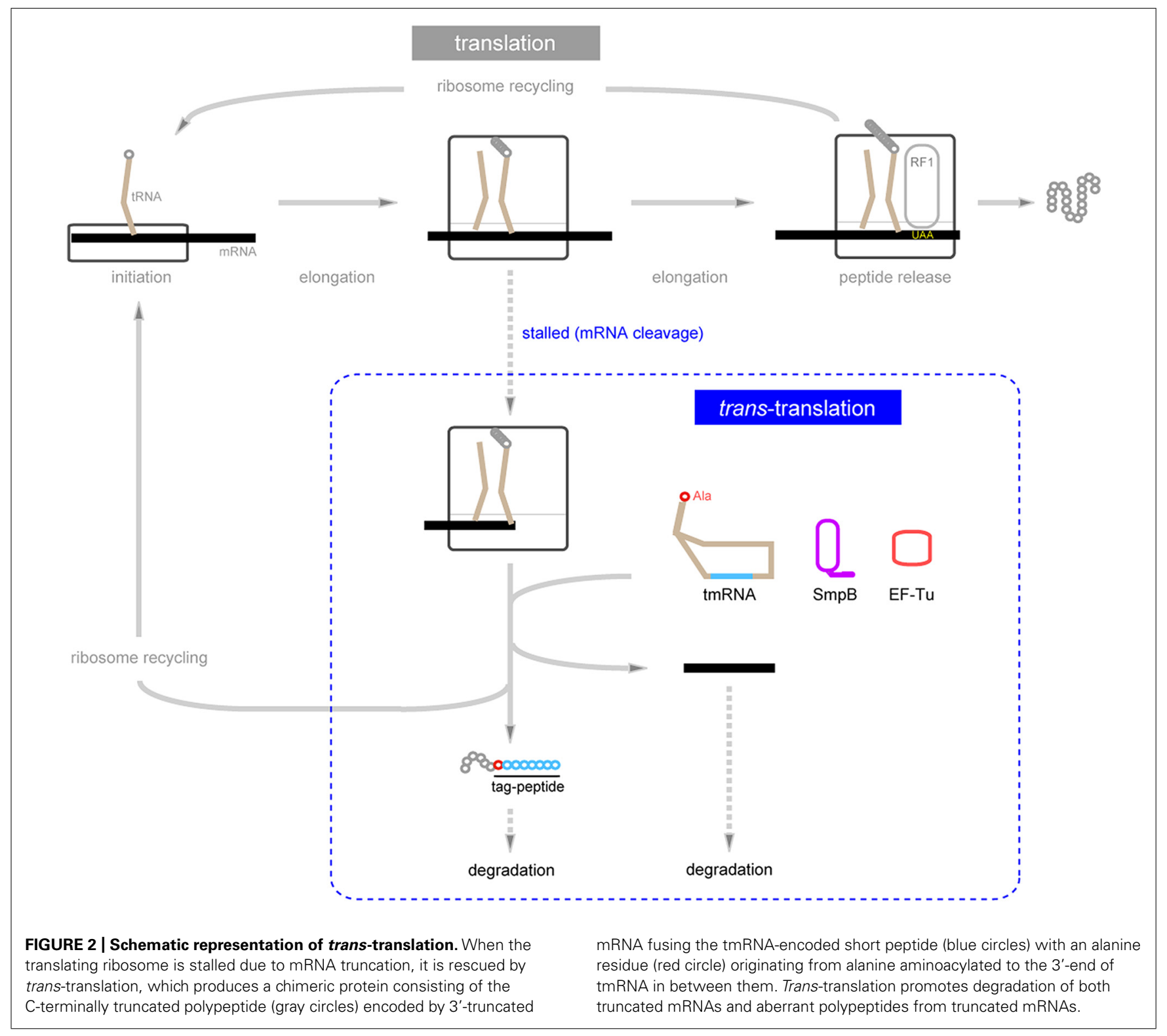

in the ribosome in addition to the unstructured conformation in solution: an extended conformation from the A-site to the downstream tunnel along the mRNA path as an $\alpha$-helical structure and a folded conformation around the mRNA path in the P-site (Kurita et al., 2007, 2010).

On the basis of these SmpB properties, the trans-translation process can be described in more detail (Figure 3). AlatmRNA.SmpB-EF-Tu.GTP enters the vacant A-site of the stalled ribosome. GTP hydrolysis induces a conformational change of the stalled complex to release EF-Tu.GDP, allowing accommodation of Ala-TLD.SmpB in the A-site. During this process, the C-terminal tail of SmpB interacts with the mRNA path extending towards the mRNA entry channel. Subsequently, Ala-TLD in the A-site receives the nascent polypeptide chain from peptidyltRNA in the P-site, and the resulting peptidyl-Ala-TLD-SmpB translocates from the A-site to the $\mathrm{P}$-site. During this process, the
C-terminal tail of SmpB dissociates from the mRNA entry channel and binds around the site of codon-anticodon interaction in the P-site with change in its conformation from the extended structure to the folded structure, which in turn promotes release of mRNA from the ribosome. The conformational change of the Cterminal tail concomitant with translocation makes the A-site free, thereby allowing introduction of the resume codon of tmRNA into the decoding region. This model has been supported by results of structural studies of several trans-translation intermediates. Cryo-EM studies have revealed three kinds of intermediates in the pre-accommodated, accommodated, and translocated states (Kaur et al., 2006; Cheng et al., 2010; Fu et al., 2010; Weis et al., 2010a,b). In all of them, SmpB and TLD occupy the lower and upper halves, respectively, of the tRNA-binding sites. Although the C-terminal tail of SmpB has not been identified in these maps due to low resolution, its interaction with the mRNA path has clearly 


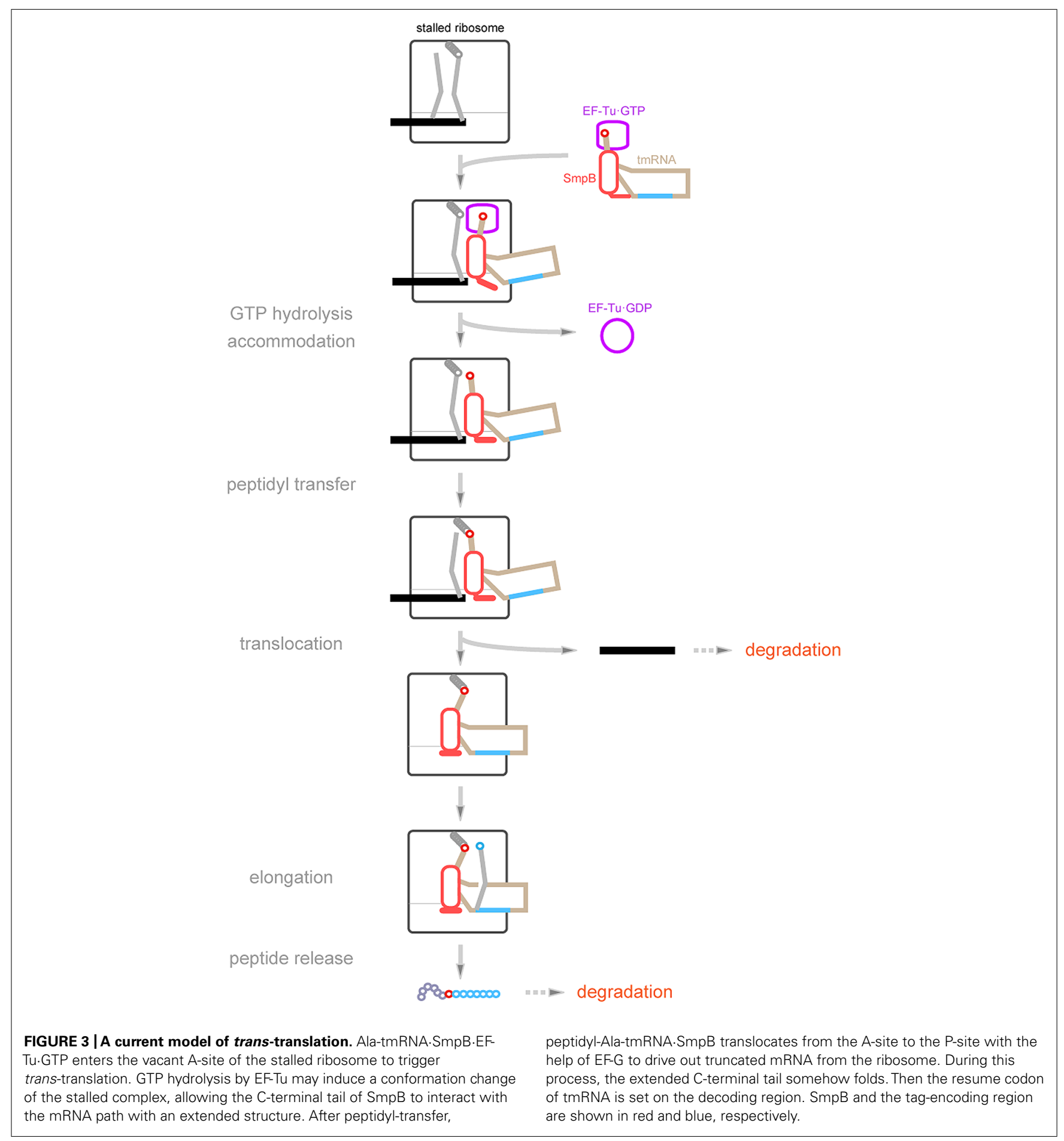

been shown in a crystal structure of a pre-accommodation state complex of trans-translation containing kirromycin (Neubauer et al., 2012).

This model can explain why trans-translation preferentially occurs at the ribosome stalled on mRNA with a shorter $3^{\prime}$ extension, which has been exemplified in vitro (Ivanova et al., 2004; Asano et al., 2005): the C-terminal tail of SmpB competes with the $3^{\prime}$-extension of mRNA for the mRNA entry channel. A chemical footprinting study has suggested that SmpB interacts with A1492, A1493, and G530 in 16S rRNA, which form the decoding region (Nonin-Lecomte et al., 2009). However, these nucleotides can be changeable without loss of both peptidyl-transferase and GTP hydrolytic activities in trans-translation, indicating much lower significance of these decoding nucleotides for trans-translation (Miller et al., 2011). In a crystal structure of a Thermus thermophilus pre-accommodation state complex of trans-translation, 
G530 stacks with a residue (Y127) around the start of the Cterminal tail of SmpB (Neubauer et al., 2012). Recently, Miller and Buskirk (2014) have found that the corresponding residue in E. coli SmpB (H136) has a crucial role in GTP hydrolysis, leading to the proposal that stacking of this residue with G530 triggers GTP hydrolysis.

EF-G promotes release of truncated mRNA from the stalled ribosome after peptidyl transfer to Ala-tmRNA, suggesting the presence of a canonical translocation-like step in the transtranslation process (Ivanova et al., 2005). During this event, SmpB must pass through the barrier between the A-site and P-site, and tmRNA must enter the inside of the mRNA entry channel to set the resume codon in the decoding region. Consistently, in a cryo-EM map of a translocational intermediate complex containing EF-G and fusidic acid, both bridge $\mathrm{B}$ la, which serves as a barrier between the A-site and P-site, and latch, which is usually closed by the interaction between the head (helix 34) and body (G530 region) to form the mRNA tunnel, are open (Ramrath et al., 2012). Precise positioning of the resume codon at the decoding region requires the sequence just upstream of the resume codon at positions -6 to +1 (Williams et al., 1999; Lee et al., 2001), and this sequence is recognized by the globular domain of SmpB (Konno et al., 2007), suggesting that $\mathrm{SmpB}$ bridges two separate domains of tmRNA in the P-site to determine the resume codon for tag-translation presumably just after translocation. This is in agreement with cryo-EM maps of translocated state complexes of trans-translation (Figure 1B; Fu et al., 2010; Weis et al., 2010b). Another study has suggested the importance of the $\mathrm{C}$-terminal tail of $\mathrm{SmpB}$ and its interaction with the start GCA codon on tmRNA for determination of the start point of tag-peptide translation (Camenares et al., 2013). Taken together, the results suggest that the interaction between tmRNA and SmpB is more important for resume point determination than the interaction between tmRNA and the ribosome. It should be noted that some kinds of aminoglycosides that bind the decoding region shift the resume point of tag-translation (Takahashi et al., 2003; Konno et al., 2004).

Although several examples of the potential molecular mimicry of tRNA by a translation factor have been reported, $\mathrm{SmpB}$ is the sole molecule that has been assumed to mimic the dynamic behavior of tRNA throughout all of the classical and hybrid states, $\mathrm{A} / \mathrm{T}$, $\mathrm{A} / \mathrm{A}, \mathrm{A} / \mathrm{P}, \mathrm{P} / \mathrm{P}$, and $\mathrm{P} / \mathrm{E}$, in the translating ribosome. The ribosomal protein $\mathrm{S} 1$, which has been identified as a tmRNA-binding protein (Wower et al., 2000), is not thought to participate in the early stage of trans-translation, at least until the first translocation (Qi et al., 2007; Takada et al., 2007).

\section{REQUIREMENT OF MRNA CLEAVAGE FOR TRANS-TRANSLATION}

Because the tag-sequence serves as a degradation signal, transtranslation products are hardly detected in the cell or its extract, although they become accumulated and thus detectable when the tag-encoding sequence of tmRNA is engineered. It has long been believed that trans-translation occurs around the $3^{\prime}$-end of truncated mRNA lacking a stop codon (non-stop mRNA) in the stalled ribosome since publication of the results of an earlier in vivo study using an artificial mRNA (Keiler et al., 1996). Non-stop mRNA can be produced either unexpectedly or in a programmed fashion, and a similar situation can also arise when the normal termination codon is read through in the presence of a non-sense suppressor tRNA (Ueda et al., 2002) or a miscoding drug (Abo et al., 2002). Proteomic analyses have identified endogenous trans-translation products from various bacterial sources, indicating that transtranslation preferentially occurs at specific sites of specific mRNAs (Roche and Sauer, 2001; Collier et al., 2002; Fujihara et al., 2002; Hong et al., 2007; Barends et al., 2010). Consequently, several situations that promote trans-translation in the middle of mRNA have been focused on: translational pausing due to a rare codon (Roche and Sauer, 1999), an inefficient termination codon (Roche and Sauer, 2001; Hayes et al., 2002a; Sunohara et al., 2002) and a programmed stalling sequence (Collier et al., 2004) induces transtranslation. However, whether trans-translation actually occurs in the middle of mRNA without cleavage has been controversial. It has been found that a bacterial toxin, RelE, cleaves an mRNA specifically at the A-site in the stalled ribosome (Pedersen et al., 2003). RelE is usually inactivated by an antitoxin, RelB, and it is activated by degradation of RelB by Lon protease upon amino acid starvation. Yet, the finding of an A-site-specific endoribonuclease has supported the idea that mRNA cleavage is the prerequisite for trans-translation. Ribosome stalling induces cleavage of mRNA at the A-site even in a cell lacking RelE or several other endoribonucleases (Hayes and Sauer, 2003; Sunohara et al., 2004a,b; Li et al., 2008), indicating the involvement of an as-yet-unidentified ribonuclease or the ribosome itself in mRNA cleavage. It has also been reported that the $3^{\prime}-5^{\prime}$ exoribonulease activity of RNase II is an important prerequisite for A-sitespecific mRNA cleavage (Garza-Sánchez et al., 2009). Besides RelE, several kinds of ribosome-dependent endoribonucleases, each having a specific antitoxin, have been identified in E. coli (Feng et al., 2013).

In vitro studies have clearly shown that trans-translation can occur in the middle of mRNA, although the efficiency of transtranslation is drastically decreased with increasing length of the $3^{\prime}$-extension from the stalled position (Ivanova et al., 2004; Asano et al., 2005). This is in agreement with results of structural studies showing that the $\mathrm{C}$-terminal tail of $\mathrm{SmpB}$ occupies the mRNA path in the early stage of trans-translation so that it competes with the $3^{\prime}$-extension of mRNA (Kurita et al., 2010; Neubauer et al., 2012).

Proteomic studies have shown that trans-translation preferentially occurs at the proline codon just preceding the stop codon (Hayes et al., 2002a,b). Asp-Pro, Glu-Pro, Pro-Pro, Ile-Pro, and Val-Pro are favorable C-terminal dipeptides for trans-translation, suggesting an additional importance of the penultimate residue. In fact, Asp-Pro and Pro-Pro are unusually underrepresented at the C-terminus in most bacterial proteins. Due to the structural irregularity of proline having a secondary amine instead of the primary amine, peptidyl-Pro-tRNA ${ }^{\text {Pro }}$ in the A-site would interfere with the access of peptide release factor (Janssen and Hayes, 2009), rather than that of the Ala-tmRNA.SmpB.EFTu.GTP complex. Consistently, limited amounts of aminoacyltRNA or release factor induce trans-translation, indicating competition of trans-translation with aminoacyl-tRNA and release factor for sense and non-sense codons, respectively, in the stalled ribosome (Ivanova etal., 2004; Asano etal., 2005; Li et al., 2007). Consecutive proline residues also affect 
peptidyl-transfer during the elongation process to cause translational arrest, which can be rescued by EF-P (Doerfel et al., 2013; Ude et al., 2013).

These in vivo and in vitro studies together have settled the controversy shown above: translation can stall even in the middle of mRNA in some situations, and this kind of stalled ribosome can be a potential target for trans-translation, although it would substantially occur only after cleavage of mRNA around the A-site by RelE or another as-yet-unidentified ribonuclease with the help of a $3^{\prime}-5^{\prime}$ exoribonuclease RNase II.

\section{TRANS-TRANSLATION AS QUALITY CONTROL SYSTEMS OF PROTEIN} AND MRNA

As described above, the most significant role of trans-translation is to promote recycling of stalled ribosomes in the cell. Transtranslation is thought to have additional roles as quality control systems of protein and mRNA.
Most trans-translation products would be non-functional, and thus their accumulation might be deleterious for the cell. To avoid this situation, the tag-peptide and in turn the trans-translation products are promptly degraded in the cell by cytoplasmic ATPdependent proteases $\left(\mathrm{AAA}^{+}\right.$proteases), including ClpXP, ClpAP, Lon and FtsH, and the periplasmic protease Tsp (Prc; Figure 4). ClpX or ClpA recognizes the C-terminal ALAA sequence of the tag-peptide to unfold the trans-translation products in an ATPdependent fashion for degradation by its partner ClpP peptidase (Gottesman et al., 1998). The tag-peptide specifically binds to a protein, SspB, to increase its affinity to $\mathrm{ClpX}$, and consequently ClpXP is thought to play the dominant role in degradation of trans-translation products at least in $\beta$ - and $\gamma$-proteobacteria (Flynn etal., 2001) and perhaps in $\alpha$-proteobacteria (Lessner et al., 2007). Lon participates in degradation of trans-translation products under stressful conditions (Choy et al., 2007). FtsH is anchored to the cytoplasmic side of the inner membrane

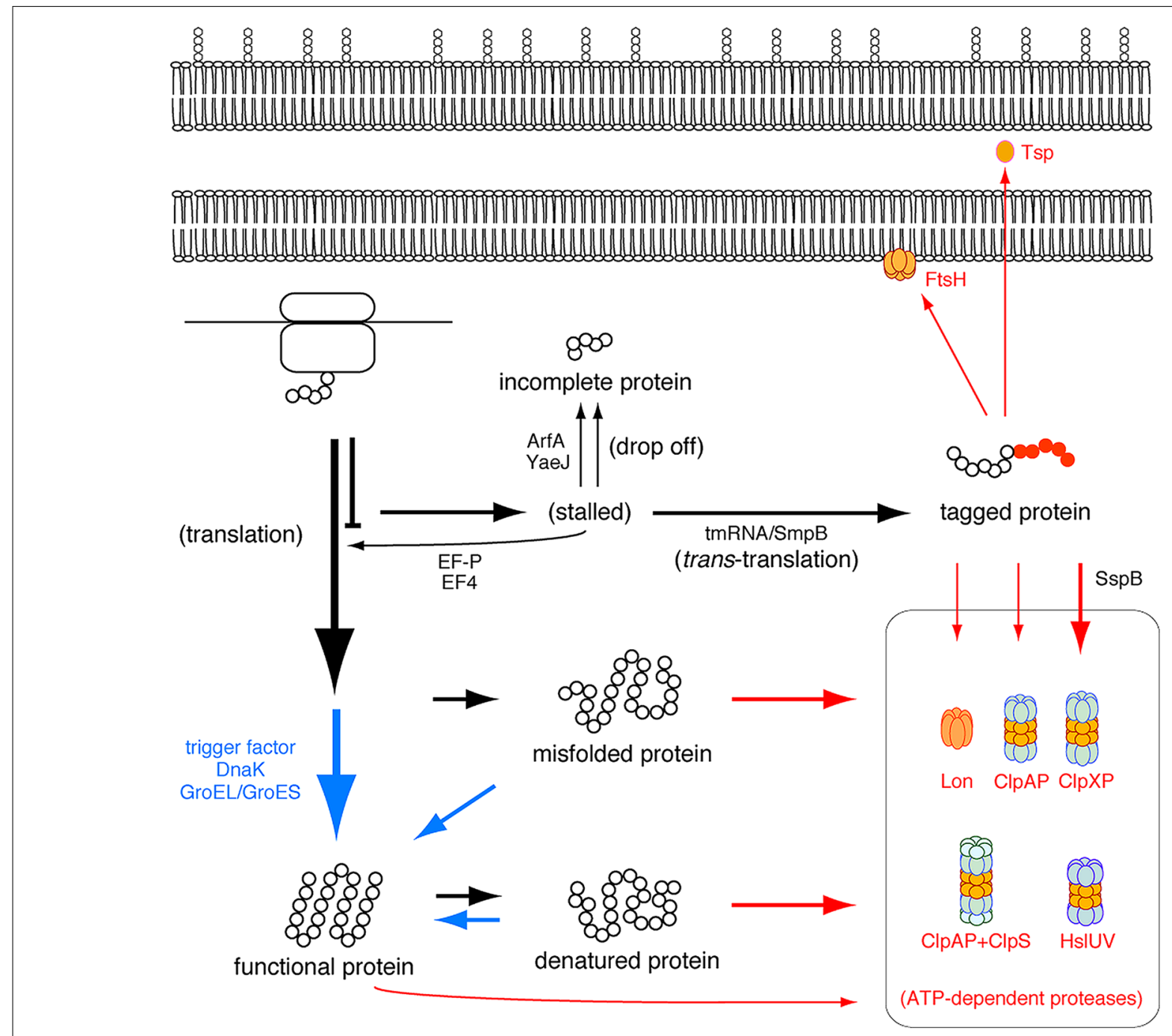

FIGURE 4 | Ribosome rescue pathways together with folding and degradation pathways in an E. coli cell. Folding and degradation pathways are shown in blue and red, respectively. 
to degrade the membrane-associated trans-translation products (Herman et al., 1998). The C-terminal ALAA sequence of the tagpeptide required for ClpXP and ClpAP is highly conserved among bacteria except Mycoplasma, in which the tag-peptide terminates with AFA instead of ALAA. This can be addressed by the absence of ClpXP, ClpAP, and Tsp in Mycoplasma (Gur and Sauer, 2008; Ge and Karzai, 2009).

While trans-translation is induced by cleavage of mRNA in the stalled ribosome as described above, trans-translation also promotes further degradation of non-stop mRNA (Yamamoto et al., 2003). Trans-translation would expose the $3^{\prime}$ end of non-stop mRNA sequestered by the stalled ribosome, facilitating the access of $3^{\prime}-5^{\prime}$ exoribonuclease for degradation of non-stop mRNA. It should be a great advantage for the cell, considering that ribosome stalling would be repeated until non-stop mRNA is degraded, even if the stalled ribosome at the $3^{\prime}$ end of the polysome is rescued by trans-translation. RNase $\mathrm{R}$ is a likely candidate for such an exoribonuclease (Oussenko et al., 2005; Mehta et al., 2006; Richards et al., 2006; Ge et al., 2011). E. coli RNase R makes a complex with tmRNA and SmpB (Karzai and Sauer, 2001) via direct interaction with SmpB (Liang and Deutscher, 2010). It is induced under stress conditions in E. coli (Chen and Deutscher, 2005) and is involved in cell cycle-regulated degradation of tmRNA in Caulobacter crescentus (Hong et al., 2005). E. coli RNase R is acetylated in exponential phase, resulting in the exponential phase-specific degradation via tighter binding to tmRNA.SmpB (Liang et al., 2011).

\section{PHYSIOLOGICAL SIGNIFICANCE OF TRANS-TRANSLATION}

The apparent universality of the trans-translation system among bacteria suggests some biological significance of this system. Indeed, it is essential for some bacteria including Neisseria gonorrhoeae (Huang et al., 2000), Mycoplasma genitalium (Hutchison et al., 1999), Haemophilus influenzae (Akerley et al., 2002), Helicobacter pylori (Thibonnier et al., 2008), and Shigella flexneri (Ramadoss et al., 2013a), and its depletion causes a wide variety of disorders. Since its lack causes avirulence of some infectious bacteria, the trans-translation system has been focused on as an effective target for antibiotics (Shi et al., 2011; Ramadoss et al., 2013b).

Many of these defective phenotypes are caused by a defect in the trans-translation reaction rather than degradation of the transtranslation products (Keiler, 2008). This suggests that ribosome recycling is more important for the cell than preventing accumulation of non-functional proteins. Upon starvation of amino acids, supply of amino acids from trans-translation products should become important for new protein synthesis (Pedersen et al., 2003; Li et al., 2008).

Trans-translation is often employed for regulation of gene expression. In E. coli, tmRNA-mediated trans-translation targets mRNA for LacI, a repressor of the lactose operon, to accelerate its degradation upon glucose depletion, leading to derepression of the lac operon (Abo et al., 2000). In Bacillus subtilis, trans-translation occurs around the catabolite responsive element (cre) sequence, a binding site of the repressor protein catabolite control protein A (CcpA), within the coding region of several mRNAs including TreP mRNA for trehalose phosphorylase (Fujihara et al., 2002).
Binding of CcpA to the cre sequence would induce a transcriptional roadblock to produce truncated mRNA (Ujiie et al., 2009). In C. crescentus, the cell cycle (Keiler and Shapiro, 2003a) and the initiation of DNA replication (Keiler and Shapiro, 2003b; Hong et al., 2007) are controlled by trans-translation.

There is accumulating evidence for increased importance of tmRNA under stressful conditions, such as high or low temperature (Oh and Apirion, 1991; Muto et al., 2000; Shin and Price, 2007), nutrient starvation (Oh and Apirion, 1991; Okan et al., 2006; Abe etal., 2008), ethanol treatment (Muto et al., 2000), cadmium treatment (Muto et al., 2000), and acid exposure (Thibonnier etal., 2008). Stresses might increase the frequency of aberrant translation in cells, which can be rescued by transtranslation. Consistently, the total amount of trans-translation products increases under stressful conditions (Fujihara et al., 2002). Perhaps in response to the increased requirement of the trans-translation system, the intracellular level of tmRNA or SmpB increases with an increase in stress in some bacteria (Muto et al., 2000; Palecková et al., 2007; Rezzonico et al., 2007).

The trans-translation system sometimes regulates other stress response systems possibly via expression of a global regulator. For example, depletion of tmRNA induces heat shock response in $E$. coli (Munavar et al., 2005). The expression level of the sigma factor RpoS (sigma S), which controls the expression of a series of genes involved in general stress response, is positively controlled by trans-translation in E. coli (Ranquet and Gottesman, 2007). The involvement of trans-translation in the extracellular stressresponse pathway via another sigma factor, RpoE (sigma E), has also been suggested (Ono et al., 2009). Other stress-related proteins including the molecular chaperone DnaK are regulated by trans-translation in streptomycetes (Barends et al., 2010). Interestingly, the expression of ArfA, an alternative ribosome rescue system (described in a later subsection), is regulated by trans-translation (Chadani et al., 2011a; Garza-Sánchez et al., 2011).

\section{EVOLUTIONARY ASPECTS OF TRANS-TRANSLATION}

Although it is not essential for viability in most bacteria, tmRNA is present universally in the bacterial kingdom and in some plastids or mitochondria of some protists. The tRNA-like secondary structure of TLD as well as several tRNA-specific consensus sequences is highly conserved except for the deformed D-arm structure, which has an extensive interaction with SmpB. In addition, the third base-pair position of the amino acid acceptor stem is completely conserved as $\mathrm{G}-\mathrm{U}$, which serves as a potent identity determinant for recognition by alanyl-tRNA synthetase (AlaRS). Alanine might not be an absolute prerequisite for trans-translation as the amino acid aminoacylated to tmRNA as exemplified by Nameki etal. (1999a). However, AlaRS might be the most preferable aminoacyl-tRNA synthetase for tmRNA, considering the unique recognition mode of AlaRS depending largely on the acceptor stem instead of the anticodon. The tRNA-like structure would also be significant for recognition by EF-Tu and RNase $\mathrm{P}$ as well as for ribosome binding. In contrast to the high degree of conservation of TLD, there is variation in the pseudoknot-rich region (Nameki etal., 1999b; Williams, 2002). Plastid tmRNA has fewer or no pseudoknot structures (Gueneau de Novoa and Williams, 2004). Indeed, at least the last three of four pseudoknots 
of E. coli tmRNA are dispensable for trans-translation in vitro (Nameki et al., 2000), although they participate in proper folding and processing of tmRNA (Wower et al., 2004). TLD and the pseudoknot-rich region are linked by a long degenerated helix, which protrudes from TLD in a direction corresponding to that of the long variable arm of class II tRNA (Figure 1B; Bessho et al., 2007). This direction should be conserved within the constraints of the tRNA-like dynamic behavior of tmRNA in the limited space of the ribosome, although the sequence of the connector helix is less conserved.

In some lineages of $\alpha$-proteobacteria, $\beta$-proteobacteria, cyanobacteria, and mitochondria of lower eukaryotes, tmRNA is separated into two pieces, a $5^{\prime}$-coding piece typically including only two pseudoknots (PK1 and PK2) with the tag-encoding region in between and a $3^{\prime}$-amino acid acceptor piece, and the two pieces join together by base-pairing to form into a tRNA-like structure similar to that in one-piece tmRNA (Figure 1A; Keiler et al., 2000; Williams, 2002; Sharkady and Williams, 2004). The gene for two-piece tmRNA is circularly permuted (Keiler et al., 2000; Williams, 2002; Mao et al., 2009), and the permuted precursor might be processed into a mature two-piece tmRNA probably with the help of RNase $\mathrm{P}$ and tRNase Z. A similar processing strategy has been found in the circularly permuted tRNA gene in some primitive eukaryotes or archaebacteria (Soma et al., 2007). The two-piece tmRNA in $C$. crescentus belonging to $\alpha$-proteobacteria has been shown to actually function in trans-translation (Keiler etal., 2000). Either one-piece or two-piece tmRNA is present in mitochondrial genome of some groups of protists (jakobids; Jacob et al., 2004). They lack a tag-encoding sequence as well as pseudoknots, arguing against their capacity for bacterial type of trans-translation.

SmpB together with tmRNA is universally present in bacteria. Plastid tmRNA is encoded by the plastid genome, while plastid $\mathrm{SmpB}$ is encoded by the nuclear genome and it is imported from the cytoplasm (Jacob etal., 2005). Up to now, there has been no report about mitochondrial SmpB. Both tmRNA and SmpB should have been required at the birth of trans-translation. The gene for tmRNA might have been formed by insertion of something into a tRNA Ala gene. In contrast, no one can envisage the origin of SmpB because of the absence of its homologue.

\section{DIVERSITY OF RESCUE SYSTEMS OF STALLED TRANSLATION}

As described above, trans-translation targets various kinds of translational pausing due to a rare codon, an inefficient termination codon or a programmed stalling sequence, but after cleavage of mRNA. The bacterial cell has alternative mechanisms to rescue the stalled ribosome (Figure 4; Himeno, 2010).

Peptidyl-tRNA hydrolase (Pth) has an activity to hydrolyze the linkage between tRNA and the nascent polypeptide of peptidyltRNA after it drops off from the ribosome. Drop-off is enhanced by RRF alone, RRF together with RF3 (Heurgué-Hamard et al., 1998; Gong et al., 2007) or RRF, IF3, and EF-G (Singh et al., 2008). Drop-off was initially assumed to occur in the earlier cycles of elongation. This seems reasonable considering that a longer nascent polypeptide chain would prevent release of peptidyl-tRNA from the peptide channel of the translating ribosome. However, dropoff has been shown to efficiently occur at the $3^{\prime}$ end of non-stop
mRNA in the absence of tmRNA (Kuroha et al., 2009). Overexpression of tmRNA suppresses the temperature-sensitive phenotype of Pth (Singh and Varshney, 2004), suggesting that Pth contributes not only to hydrolyzing the dropped-off peptidyl-tRNA but also to rescuing the stalled ribosome or suggesting that trans-translation can substitute for spontaneous or factor-promoting drop-off and the following peptidyl-tRNA hydrolysis by Pth.

It has recently been found that two proteins, ArfA (YhdL) and YaeJ (ArfB), facilitate rescue of the stalled ribosome. A single knockout of either E. coli ArfA or tmRNA is viable, whereas a double knockout is lethal, explaining why tmRNA is not essential in many bacteria (Chadani et al., 2010). The ribosome rescue activity of ArfA was initially shown using E. coli crude extract (Chadani et al., 2010). However, ArfA alone does not have an activity to hydrolyze peptidyl-tRNA in the P-site possibly due to the absence of a typical GGQ catalytic motif, and it requires the help of RF-2 (Chadani et al., 2012; Shimizu, 2012). RF-2 usually acts as a UAA or UGA codon-dependent release factor, while it serves as a stop codon-independent release factor in the presence of ArfA. Intriguingly, translation for ArfA protein is stalled near the $3^{\prime}$-terminus of its mRNA due to cleavage by RNase III, and consequently ArfA is usually degraded via the trans-translation system, and only when the cellular trans-translation activity becomes diminished, is C-terminally truncated but active ArfA synthesized via spontaneous drop-off or ArfA-mediated release of the nascent polypeptide (Garza-Sánchez et al., 2011; Chadani et al., 2011a). Thus, the ArfA-mediated ribosome rescue system is considered to be a backup system for trans-translation. YaeJ has also been shown to rescue the ribosomes stalled at the $3^{\prime}$ end of a non-stop mRNA in vitro (Handa et al., 2011) and in vivo (Chadani et al., 2011b). A double knockout of E. coli ArfA and tmRNA is lethal as described above, whereas overexpression of YaeJ makes it viable (Chadani et al., 2011a). Unlike ArfA, YaeJ alone has an activity to hydrolyze peptidyl-tRNA in the P-site of the stalled ribosome, as expected from the similar sequence and structure to those of the catalytic domain of bacterial class I release factor having a GGQ motif. YaeJ is likely to act as a stop codon-independent peptide chain release factor since it lacks a stop codon-recognition domain and instead it is replaced by a C-terminal basic-residue-rich extension that might be unstructured in solution (Handa et al., 2010). In a crystal structure of E. coli YaeJ in complex with the stalled ribosome from T. thermophilus, the C-terminal extension of YaeJ, like that of SmpB, binds along the mRNA path of the stalled ribosome extending to the downstream mRNA tunnel with an $\alpha$-helical structure (Gagnon et al., 2012). ArfA as well as Ala-tmRNA.SmpB·EF$\mathrm{Tu}(\mathrm{GTP})$ does not favor the long $3^{\prime}$ extension of mRNA from the decoding region upon entrance to the stalled ribosome, while YaeJ is less sensitive (Shimizu, 2012). Thus bacterial cells are equipped with multiple systems to cope with stalled translation, and they are therefore often still viable even when they lose the trans-translation system. Judging from phenotypes of factor-depleted cells, the trans-translation system must be the primary ribosome rescue system.

There are some reports about stress-specific ribosome rescue systems. The heat shock protein HSP15 has been shown to bind to the dissociated 50S subunit with a nascent protein (Korber et al., 2000). Upon exposure to a high temperature, a fraction 
of translating ribosomes might prematurely be dissociated into subunits, although peptidyl-tRNA remains bound to the dissociated 50S subunit unless the nascent peptide is short. In this 50S subunit, HSP15 fixes peptidyl-tRNA at the P-site to make the A-site free presumably for entrance of a peptide release factor (Jiang et al., 2009). High intracellular magnesium ion concentration or low temperature causes translational arrest after defective translocation. It also promotes release of a GTPase, EF4 (LepA), which is usually stored in the cell membrane, into the cytoplasm to rescue the translational arrest by back translocation (Pech et al., 2011).

Translation often stalls at a specific site on an mRNA in a programmed fashion. As in the case of ArfA expression described above (Chadani et al., 2011a; Garza-Sánchez et al., 2011), translational arrest is sometimes used for repression of gene expression via trans-translation. On the other hand, a stalled ribosome often prevents access of rescue machineries to keep translational arrest for regulation of gene expression. E. coli tryptophanase (tna) operon is induced by tryptophan via the translational arrest of the leader peptide (TnaC) by inhibiting hydrolysis of

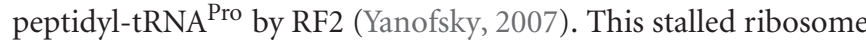
is not rescued by trans-translation in the presence of tryptophan, although it is rescued slowly by RRF and RF3, leading to dropoff (Gong et al., 2007). The ribosome is also stalled at an internal proline codon of E. coli secM mRNA, which up-regulates the translation of the downstream SecA-encoding sequence presumably by disrupting the secondary structure that sequesters the ribosome binding site (Muto et al., 2006). This translational arrest is caused by inefficient peptidyl-transfer of Pro-tRNA ${ }^{\text {Pro }}$ in the A-site to the nascent peptidyl-tRNA in the P-site, which inhibits entrance of Ala-tmRNA to the A-site and the A-site specific cleavage of mRNA (Garza-Sánchez et al., 2006). The translation of B. subtilis yidC mRNA is regulated by translational arrest at multiple sites on the upstream mifM mRNA (Chiba et al., 2009; Chiba and Ito, 2012). Puromycin is less reactive to this translational arrest, suggesting that ribosome rescue machineries including Ala-tmRNA.SmpB-EF-Tu(GTP) are also less accessible to the Asite of this stalled ribosome. Consecutive proline codons cause a translational arrest due to inefficient peptidyl-transfer between peptidyl-(Pro)n-tRNA in the P-site and Pro-tRNA in the A-site (Doerfel etal., 2013; Ude etal., 2013). In this case, the A-site is occupied by Pro-tRNAPro, and in turn Ala-tmRNA.SmpB.EF$\mathrm{Tu}(\mathrm{GTP})$, ArfA or YaeJ would fail to access this stalled ribosome. Instead, the peptidyltransferase center is modulated by EF-P binding to the region between the P-site and E-site to resume peptidyltransfer (Blaha et al., 2009). Pro-Pro-Pro and Gly-Pro-Pro arrest sequences, which can be rescued by EF-P, are often found in bacterial genes, and they might be programmed for regulation of gene expression.

Pth is essential for bacteria and is widely distributed among the other domains. While the trans-translation system universally exists in bacteria, YaeJ is distributed among Gram-negative bacteria and ArfA shows more limited distribution within enterobacteria. EF-P is conserved among bacteria and its homologue (a/eIF5A) is universally present in archaea and eukaryotes. EF4 is universally conserved among bacteria. Neither tmRNA nor $\mathrm{SmpB}$ is present in the cytoplasm of eukaryotes, where a complex of Dom34p (Pelota) and the GTP-binding protein Hbs1 promotes subunit dissociation of the stalled ribosome and drop-off of peptidyl-tRNA (Shoemaker et al., 2010) in concert with an ATPase, ABCE1 (Pisareva et al., 2011). The Dom34p.Hbs1 complex is structurally similar to the eRF1-eRF3 complex or the aminoacyl-tRNA.EF-Tu complex (Chen et al., 2010), although the GGQ motif is absent in Dom34, and peptidyl-tRNA hydrolysis is assumed to be catalyzed by Pth after drop-off. In mitochondria, two protein factors partially similar to the bacterial class I release factor, ICT1 (a homologue of YaeJ) and C12orf65, both lacking a stop codon-recognition domain while retaining the catalytic GGQ motif, participate in ribosome rescue (Handa et al., 2010; Richter et al., 2010; Kogure et al., 2012, 2014). ICT1 (YaeJ), but not C12orf65, has an insertion of an $\alpha$-helix in the GGQ domain, and thus ICT1 is less similar to class I release factor. C12orf65 has been found in very limited bacteria. Collectively, various kinds of release factor homologues, YaeJ, ICT1, C12orf65, ArfA/RF2, Dom34p (Pelota), and Hbs1, have been found to participate in ribosome rescue. The trans-translation system is unique in that it employs a small RNA and that it prevents accumulation of non-functional proteins from truncated mRNA in the cell.

\section{ACKNOWLEDGMENTS}

The authors are grateful to all those who have been involved in this work. This work was supported by a grant-in-aid for Scientific Research from the Ministry of Education, Science, Sports and Culture, Japan to Hyouta Himeno, grants-in-aid for Scientific Research (B) and (C) from the Japan Society for the Promotion of Science to Akira Muto and grants-in-aid for Young Scientists from the Japan Society for the Promotion of Science to Daisuke Kurita.

\section{REFERENCES}

Abe, T., Sakaki, K., Fujihara, A., Ujiie, H., Ushida, C., Himeno, H., et al. (2008). tmRNA-dependent trans-translation is required for sporulation in Bacillus subtilis. Mol. Microbiol. 69, 1491-1498. doi: 10.1111/j.1365-2958.2008.06381.x

Abo, T., Inada, T., Ogawa, K., and Aiba, H. (2000). SsrA-mediated tagging and proteolysis of LacI and its role in the regulation of lac operon. EMBO J. 19, 3762-3769. doi: 10.1093/emboj/19.14.3762

Abo, T., Ueda, K., Sunohara, T., Ogawa, K., and Aiba, H. (2002). SsrA-mediated protein tagging in the presence of miscoding drugs and its physiological role in Escherichia coli. Genes Cells 7, 629-638. doi: 10.1046/j.1365-2443.2002.00549.x

Akerley, B. J., Rubin, E. J., Novick, V. L., Amaya, K., Judson, N., and Mekalanos, J. J. (2002). A genome-scale analysis for identification of genes required for growth or survival of Haemophilus influenzae. Proc. Natl. Acad. Sci. U.S.A. 99, 966-971. doi: 10.1073/pnas.012602299

Asano, K., Kurita, D., Takada, K., Konno, T., Muto, A., and Himeno, H. (2005). Competition between trans-translation and termination or elongation of translation. Nucleic Acids Res. 33, 5544-5552. doi: 10.1093/nar/gki871

Barends, S., Karzai, A. W., Sauer, R. T., Wower, J., and Kraal, B. (2001). Simultaneous and functional binding of SmpB and EF-Tu-GTP to the alanyl acceptor arm of tmRNA. J. Mol. Biol. 314, 9-21. doi: 10.1006/jmbi.2001.5114

Barends, S., Wower, J., and Kraal, B. (2000). Kinetic parameters for tmRNA binding to alanyl-tRNA synthetase and elongation factor Tu from Escherichia coli. Biochemistry 39, 2652-2658. doi: 10.1021/bi992439d

Barends, S., Zehl, M., Bialek, S., de Waal, E., Traag, B. A., Willemse, J., et al. (2010). Transfer-messenger RNA controls the translation of cell-cycle and stress proteins in Streptomyces. EMBO Rep. 11, 119-125. doi: 10.1038/embor.2009.255

Bessho, Y., Shibata, R., Sekine, S., Murayama, K., Higashijima, K., Hori-Takemoto, C., et al. (2007). Structural basis for functional mimicry of long-variable-arm tRNA by transfer-messenger RNA. Proc. Natl. Acad. Sci. U.S.A. 104, 8293-8298. doi: 10.1073/pnas.0700402104 
Blaha, G., Stanley, R. E., and Steitz, T. A. (2009). EF-P is essential for rapid synthesis of proteins containing consecutive proline residues. Science 325, 966-970. doi: $10.1126 /$ science. 1175800

Camenares, D., Dulebohn, D. P., Svetlanov, A., and Karzai, A. W. (2013). Active and accurate trans-translation requires distinct determinants in the $\mathrm{C}$-terminal tail of SmpB protein and the mRNA-like domain of transfer messenger RNA (tmRNA) J. Biol. Chem. 288, 30527-30542. doi: 10.1074/jbc.M113.503896

Chadani, Y., Ito, K., Kutsukake, K., and Abo, T. (2012). ArfA recruits release factor 2 to rescue stalled ribosomes by peptidyl-tRNA hydrolysis in Escherichia coli. Mol. Microbiol. 86, 37-50. doi: 10.1111/j.1365-2958.2012.08190.x

Chadani, Y., Matsumoto, E., Aso, H., Wada, T., Kutsukake, K., Sutou, S., et al. (2011a). trans-Translation-mediated tight regulation of the expression of the alternative ribosome-rescue factor ArfA in Escherichia coli. Genes Genet. Syst. 86, 151-163. doi: 10.1266/ggs.86.151

Chadani, Y., Ono, K., Kutsukake, K., and Abo, T. (2011b). Escherichia coli YaeJ protein mediates a novel ribosome-rescue pathway distinct from SsrA- and ArfA-mediated pathways. Mol. Microbiol. 80, 772-785. doi: 10.1111/j.13652958.2011.07607.x

Chadani, Y., Ono, K., Ozawa, S., Takahashi, Y., Takai, K., Nanamiya, H., et al. (2010). Ribosome rescue by Escherichia coli ArfA (YhdL) in the absence of trans-translation system. Mol. Microbiol. 80, 772-775. doi: 10.1111/j.13652958.2011.07607.x

Chen, C., and Deutscher, M. P. (2005). Elevation of RNase R in response to multiple stress conditions. J. Biol. Chem. 280, 34393-34396. doi: 10.1074/jbc.C500333200

Chen, L., Muhlrad, D., Hauryliuk, V., Cheng, Z., Lim, M. K., Shyp, V., et al. (2010) Structure of the Dom34-Hbs1 complex and implications for no-go decay. Nat. Struct. Mol. Biol. 17, 1233-1240. doi: 10.1038/nsmb.1922

Cheng, K., Ivanova, N., Scheres, S. H., Pavlov, M. Y., Carazo, J. M., Hebert, H., et al. (2010). tmRNA.SmpB complex mimics native aminoacyl-tRNAs in the A site of stalled ribosomes. J. Struct. Biol. 169, 342-348. doi: 10.1016/j.jsb.2009.10.015

Chiba, S., and Ito, K. (2012). Multisite ribosomal stalling: a unique mode of regulatory nascent chain action revealed for MifM. Mol. Cell 47, 863-872. doi: 10.1016/j.molcel.2012.06.034

Chiba, S., Lamsa, A., and Pogliano, K. (2009). A ribosome-nascent chain sensor of membrane protein biogenesis in Bacillus subtilis. EMBO J. 28, 3461-3475. doi: 10.1038/emboj.2009.280

Choy, J. S., Aung, L. L., and Karzai, A. W. (2007). Lon protease degrades transfer-messenger RNA-tagged proteins. J. Bacteriol. 189, 6564-6571. doi: 10.1128/JB.00860-07

Collier, J., Binet, E., and Bouloc, P. (2002). Competition between SsrA tagging and translational termination at weak stop codons in Escherichia coli. Mol. Microbiol. 45, 745-754. doi: 10.1046/j.1365-2958.2002.03045.x

Collier, J., Bohn, C., and Bouloc, P. (2004). SsrA tagging of Escherichia coli SecM at its translation arrest sequence. J. Biol. Chem. 279, 54193-54201. doi: 10.1074/jbc.M314012200

Doerfel, L. K., Wohlgemuth, I., Kothe, C., Peske, F., Urlaub, H., and Rodnina, M V. (2013). EF-P is essential for rapid synthesis of proteins containing consecutive proline residues. Science 339, 85-88. doi: 10.1126/science. 1229017

Dong, G., Nowakowski, J., and Hoffman, D. W. (2002). Structure of small protein B: the protein component of the tmRNA-SmpB system for ribosome rescue. $E M B O$ J. 21, 1845-1854. doi: 10.1093/emboj/21.7.1845

Felden, B., Hanawa, K., Atkins, J. F., Himeno, H., Muto, A., Gesteland, R. F, et al. (1998). Presence and location of modified nucleotides in E. col tmRNA. Structural mimicry with tRNA acceptor branches. EMBO J. 17, 3188-3196. doi: 10.1093/emboj/17.11.3188

Felden, B., Himeno, H., Muto, A., McCutcheon, J. P., Atkins, J. F., and Gesteland, R. F. (1997). Probing the structure of the Escherichia coli 10Sa RNA (tmRNA). RNA 3, 89-103.

Feng, S., Chen, Y., Kamada, K., Wang, H., Tang, K., Wang, M., et al. (2013). YoeBribosome structure: a canonical RNase that requires the ribosome for its specific activity. Nucleic Acids Res. 41, 9549-9556. doi: 10.1093/nar/gkt742

Flynn, J. M., Levchenko, I., Seidel, M., Wickner, S. H., Sauer, R. T., and Baker, T. A. (2001). Overlapping recognition determinants within the ssrA degradation tag allow modulation of proteolysis. Proc. Natl. Acad. Sci. U.S.A. 98, 10584-10589. doi: 10.1073/pnas.191375298

Fu, J., Hashem, Y., Wower, I., Lei, J., Liao, H. Y., Zwieb, C., et al. (2010). Visualizing the transfer-messenger RNA as the ribosome resumes translation. EMBO J. 29, 3819-3825. doi: 10.1038/emboj.2010.255
Fujihara, A., Tomatsu, H., Inagaki, S., Tadaki, T., Ushida, C., Himeno, H., et al. (2002). Detection of tmRNA-mediated trans-translation products in Bacillus subtilis. Genes Cells 7, 343-350. doi: 10.1046/j.1365-2443.2002.00523.x

Gagnon, M. G., Seetharaman, S. V., Bulkley, D., and Steitz, T. A. (2012). Structural basis for the rescue of stalled ribosomes: structure of YaeJ bound to the ribosome. Science 335, 1370-1372. doi: 10.1126/science.1217443

Garza-Sánchez, F., Janssen, B. D., and Hayes, C. S. (2006). Prolyl-tRNAPro in the A-site of SecM-arrested ribosomes inhibits the recruitment of transfer-messenger RNA. J. Biol. Chem. 281, 34258-34268. doi: 10.1074/jbc.M608052200

Garza-Sánchez F., Schaub, R. E., Janssen, B. D., and Hayes, C. S. (2011). tmRNA regulates synthesis of the ArfA ribosome rescue factor. Mol. Microbiol. 80, 12041219. doi: 10.1111/j.1365-2958.2011.07638.x

Garza-Sánchez, F., Shoji, S., Fredrick, K., and Hayes, C. S. (2009). RNase II is important for A-site mRNA cleavage during ribosome pausing. Mol. Microbiol. 73, 882-897. doi: 10.1111/j.1365-2958.2009.06813.x

Ge, Z., and Karzai, A. W. (2009). Co-evolution of multipartite interactions between an extended tmRNA tag and a robust Lon protease in Mycoplasma. Mol. Microbiol. 74, 1083-1099. doi: 10.1111/j.1365-2958.2009.06923.x

Ge, Z., Mehta, P., Richards, J., and Karzai, A. W. (2011). Non-stop mRNA decay initiates at the ribosome. Mol. Microbiol. 78, 1159-1170. doi: 10.1111/j.13652958.2010.07396.x

Gong, M., Cruz-Vera, L. R., and Yanofsky, C. (2007). Ribosome recycling factor and release factor 3 action promotes TnaC-peptidyl-tRNA dropoff and relieves ribosome stalling during tryptophan induction of tha operon expression in Escherichia coli. J. Bacteriol. 189, 3147-3155. doi: 10.1128/JB.01868-06

Gottesman, S., Roche, E., Zhou, Y., and Sauer, R. T. (1998). The ClpXP and ClpAP proteases degrade proteins with carboxy-terminal peptide tails added by the SsrAtagging† †ystem. Genes Dev. 12, 1338-1347. doi: 10.1101/gad.12.9.1338

Gueneau de Novoa, P., and Williams, K. P. (2004). The tmRNA website: reductive evolution of tmRNA in plastids and other endosymbionts. Nucleic Acids Res. 32, D104-D108. doi: 10.1093/nar/gkh102

Gur, E., and Sauer, R. T. (2008). Evolution of the ssrA degradation tag in mycoplasma: specificity switch to a different protease. Proc. Natl. Acad. Sci. U.S.A. 105, 16113-16118. doi: 10.1073/pnas.0808802105

Gutmann, S., Haebel, P. W., Metzinger, L., Sutter, M., Felden, B., and Ban, N. (2003). Crystal structure of the transfer-RNA domain of transfer-messenger RNA in complex with SmpB. Nature 424, 5503-5509. doi: 10.1038/nature01831

Hanawa-Suetsugu, K., Bordeau, V., Himeno, H., Muto, A., and Felden, B. (2001). Importance of the conserved nucleotides around the tRNA-like structure of Escherichia coli transfer-messenger RNA for protein tagging. Nucleic Acids Res. 29, 4663-4673. doi: 10.1093/nar/29.22.4663

Hanawa-Suetsugu, K., Takagi, M., Inokuchi, H., Himeno, H., and Muto, A. (2002). SmpB functions in various steps of trans-translation. Nucleic Acids Res. 30, 16201629. doi: 10.1093/nar/30.7.1620

Handa, Y., Hikawa, Y., Tochio, N., Kogure, H., Inoue, M., Koshiba, S., et al. (2010). Solution structure of the catalytic domain of the mitochondrial protein ICT1 that is essential for cell vitality. J. Mol. Biol. 404, 260-273. doi: 10.1016/j.jmb.2010.09.033

Handa, Y., Inaho, N., and Nameki, N. (2011). YaeJ is a novel ribosome-associated protein in Escherichia coli that can hydrolyze peptidyl-tRNA on stalled ribosomes. Nucleic Acids Res. 39, 1739-1748. doi: 10.1093/nar/gkq1097

Hayes, C. S., Bose, B., and Sauer, R. T. (2002a). Stop codons preceded by rare arginine codons are efficient determinants of SsrA tagging in Escherichia coli. Proc. Natl. Acad. Sci. U.S.A. 99, 3440-3445. doi: 10.1073/pnas.052707199

Hayes, C. S., Bose, B., and Sauer, R. T. (2002b). Proline residues at the C terminus of nascent chains induce SsrA tagging during translation termination. J. Biol. Chem. 277, 33825-33832. doi: 10.1074/jbc.M205405200

Hayes, C. S., and Sauer, R. T. (2003). Cleavage of the A site mRNA codon during ribosome pausing provides a mechanism for translational quality control. Mol. Cell 12, 903-911. doi: 10.1016/S1097-2765(03)00385-X

Herman, C., Thévenet, D., Bouloc, P., Walker, G. C., and D’Ari, R. (1998). Degradation of carboxy-terminal-tagged cytoplasmic proteins by the Escherichia coli protease HflB (FtsH). Genes Dev. 12, 1348-1355. doi: 10.1101/gad.12. 9.1348

Heurgué-Hamard, V., Karimi, R., Mora, L., MacDougall, J., Leboeuf, C., Grentzmann, G., et al. (1998). Ribosome release factor RF4 and termination factor RF3 are involved in dissociation of peptidyl-tRNA from the ribosome. EMBO J. 17, 808-816. doi: 10.1093/emboj/17.3.808 
Himeno, H. (2010). Cellular mechanisms to rescue the ribosome stalled during translation. Mol. Microbiol. 78, 789-791. doi: 10.1111/j.1365-2958.2010.07379.x

Himeno, H., Sato, M., Tadaki, T., Fukushima, M., Ushida, C., and Muto, A. (1997). In vitro trans-translation mediated by alanine-charged 10Sa RNA. J. Mol. Biol. 268, 803-808. doi: 10.1006/jmbi.1997.1011

Hong, S.-J., Lessner, F. H., Mahen, E. M., and Keiler, K. C. (2007). Proteomic identification of tmRNA substrates. Proc. Natl. Acad. Sci. U.S.A. 104, 17128 17133. doi: $10.1073 /$ pnas.0707671104

Hong, S.-J., Tran, Q. A., and Keiler, K. (2005). Cell cycle-regulated degradation of tmRNA is controlled by RNase R and SmpB. Mol. Microbiol. 57, 565-575. doi: 10.1111/j.1365-2958.2005.04709.x

Huang, C., Wolfgang, M. C., Withey, J., Koomey, M., and Friedman, D. I. (2000). Charged tmRNA but not tmRNA-mediated proteolysis is essential for Neisseria gonorrhoeae viability. EMBO J. 19, 1098-1107. doi: 10.1093/emboj/19.5.1098

Hutchison, C. A., Peterson, S. N., Gill, S. R., Cline, R. T., White, O., Fraser, C. M., et al. (1999). Global transposon mutagenesis and a minimal mycoplasma genome. Science 286, 2165-2169. doi: 10.1126/science.286.5447.2165

Ivanova, N., Lindell, M., Pavlov, M., Holmberg Schiavone, L., Wagner, E. G., and Ehrenberg, M. (2007). Structure probing of tmRNA in distinct stages of transtranslation. RNA 13, 713-722. doi: 10.1261/rna.451507

Ivanova, N., Pavlov, M. Y., and Ehrenberg, M. (2005). tmRNA-induced release of messenger RNA from stalled ribosomes. J. Mol. Biol. 350, 897-905. doi: 10.1016/j.jmb.2005.05.033

Ivanova, N., Pavlov, M. Y., Felden, B., and Ehrenberg, M. (2004). Ribosome rescue by tmRNA requires truncated mRNAs. J. Mol. Biol. 338, 33-41. doi: 10.1016/j.jmb.2004.02.043

Jacob, Y., Seif, E., Paquet, P.-O., and Lang, B. F. (2004). Loss of the mRNAlike region in mitochondrial tmRNAs of jakobids. RNA 10, 605-614. doi: 10.1261/rna.5227904

Jacob, Y., Sharkady, S. M., Bhardwaj, K., Sanda, A. A., and Williams, K. P. (2005). Function of the SmpB tail in transfer-messenger RNA translation revealed by a nucleus-encoded form. J. Biol. Chem. 280, 5503-5509. doi: 10.1074/jbc.M409277200

Janssen, B. D., and Hayes, C. S. (2009). Kinetics of paused ribosome recycling in Escherichia coli. J. Mol. Biol. 394, 251-267. doi: 10.1016/j.jmb.2009.09.020

Jiang, L., Schaffitzel, C., Bingel-Erlenmeyer, R., Ban, N., Korber, P., Koning, R. I., et al. (2009). Recycling of aborted ribosomal 50S subunit-nascent chain-tRNA complexes by the heat shock protein Hsp15. J. Mol. Biol. 386, 1357-1367. doi: 10.1016/j.jmb.2008.10.079

Karzai, A. W., and Sauer, R. T. (2001). Protein factors associated with the SsrA-SmpB tagging and ribosome rescue complex. Proc. Natl. Acad. Sci. U.S.A. 98, 3040-3044 doi: 10.1073/pnas.051628298

Karzai, A. W., Susskind, M. M., and Sauer, R. T. (1999). SmpB, a unique RNA-binding protein essential for the peptide-tagging activity of SsrA (tmRNA). EMBO J. 18 3793-3799. doi: 10.1093/emboj/18.13.3793

Kaur, S., Gillet, R., Li, W., Gursky, R., and Frank, J. (2006). Cryo-EM visualization of transfer messenger RNA with two SmpBs in a stalled ribosome. Proc. Natl. Acad. Sci. U.S.A. 103, 16484-16489. doi: 10.1073/pnas.0607438103

Keiler, K. C. (2008). Biology of trans-translation. Annu. Rev. Microbiol. 62, 133-151. doi: 10.1146/annurev.micro.62.081307.162948

Keiler, K. C., and Shapiro, L. (2003a). tmRNA in Caulobacter crescentus is cell cycle regulated by temporally controlled transcription and RNA degradation. J. Bacteriol. 185, 1825-1830. doi: 10.1128/JB.185.6.1825-1830.2003

Keiler, K. C., and Shapiro, L. (2003b). tmRNA is required for correct timing of DNA replication in Caulobacter crescentus. J. Bacteriol. 185, 573-580. doi 10.1128/JB.185.2.573-580.2003

Keiler, K. C., Shapiro, L., and Williams, K. P. (2000). tmRNAs that encode proteolysis-inducing tags are found in all known bacterial genomes: a twopiece tmRNA functions in Caulobactor. Proc. Natl. Acad. Sci. U.S.A. 97, 7778-7783. doi: 10.1073/pnas.97.14.7778

Keiler, K. C., Waller, P. R., and Sauer, R. T. (1996). Role of a peptide tagging system in degradation of proteins synthesized from damaged messenger RNA. Science 271, 990-993. doi: 10.1126/science.271.5251.990

Kogure, H., Handa, Y., Nagata, M., Kanai, N., Güntert, P., Kubota, K., et al. (2014). Identification of residues required for stalled-ribosome rescue in the codonindependent release factor YaeJ. Nucleic Acids Res. doi: 10.1093/nar/gkt1280

Kogure, H., Hikawa, Y., Hagihara, M., Tochio, N., Koshiba, S., Inoue, Y., et al. (2012). Solution structure and siRNA-mediated knockdown analysis of the mitochondrial disease-related protein C12orf65. Proteins 80, 2629-2642. doi: 10.1002/prot.24152

Komine, Y., Kitabatake, M., and Inokuchi, H. (1996). 10Sa RNA is associated with 70 S ribosome particles in Escherichia coli. J. Biochem. 119, 463-467. doi: 10.1093/oxfordjournals.jbchem.a021264

Komine, Y., Kitabatake, M., Yokogawa, T., Nishikawa, K., and Inokuchi, H. (1994). A tRNA-like structure is present in 10Sa RNA, a small stable RNA from Escherichia coli. Proc. Natl. Acad. Sci. U.S.A. 91, 9223-9227. doi: 10.1073/pnas.91.20.9223

Konno, T., Kurita, D., Takada, K., Muto, A., and Himeno, H. (2007). A functional interaction of SmpB with tmRNA for determination of the resuming point of trans-translation. RNA 13, 1723-1731. doi: 10.1261/rna.604907

Konno, T., Takahashi, T., Kurita, D., Muto, A., and Himeno, H. (2004). A minimum structure of aminoglycosides that causes an initiation shift of trans-translation. Nucleic Acids Res. 32, 4119-4126. doi: 10.1093/nar/gkh750

Korber, P., Stahl, J. M., Nierhaus, K. H., and Bardwell, J. C. (2000). Hsp15: a ribosome-associated heat shock protein. EMBO J. 19, 741-748. doi: 10.1093/emboj/19.4.741

Kurita, D., Muto, A., and Himeno, H. (2010). Role of the C-terminal tail of SmpB in the early stage of trans-translation. RNA 16, 980-990. doi: 10.1261/rna.1916610

Kurita, D., Muto, A., and Himeno, H. (2012). In vitro trans-translation assay. Methods Mol. Biol. 905, 311-325. doi: 10.1007/978-1-61779-949-5_20

Kurita, D., Sasaki, R., Muto, A., and Himeno, H. (2007). Interaction of SmpB with ribosome from directed hydroxyl radical probing. Nucleic Acids Res. 35, 7248-7255. doi: 10.1093/nar/gkm677

Kuroha, K., Horiguchi, N., Aiba, H., and Inada, T. (2009). Analysis of nonstop mRNA translation in the absence of tmRNA in Escherichia coli. Genes Cells 14, 739-749. doi: 10.1111/j.1365-2443.2009.01304.x

Lee, S., Ishii, M., Tadaki, T., Muto, A., and Himeno, H. (2001). Determinants on tmRNA for initiating efficient and precise trans-translation: some mutations upstream of the tag-encoding sequence of Escherichia coli tmRNA shift the initiation point of trans-translation in vitro. RNA 7, 999-1012. doi: $10.1017 / \mathrm{S} 1355838201010342$

Lessner, F. H., Venters, B. J., and Keiler, K. C. (2007). Proteolytic adaptor for transfermessenger RNA-tagged proteins from alpha-proteobacteria. J. Bacteriol. 189, 272275. doi: 10.1128/JB.01387-06

Li, X., Yagi, M., Morita, T., and Aiba, H. (2008). Cleavage of mRNAs and role of tmRNA system under amino acid starvation in Escherichia coli. Mol. Microbiol. 68, 462-473. doi: 10.1111/j.1365-2958.2008.06167.x

Li, X., Yokota, T., Ito, K., Nakamura, Y., and Aiba, H. (2007). Reduced action of polypeptide release factors induces mRNA cleavage and tmRNA tagging at stop codons in Escherichia coli. Mol. Microbiol. 63, 116-126. doi: 10.1111/j.13652958.2006.05498.x

Liang, W., and Deutscher, M. P. (2010). A novel mechanism for ribonuclease regulation: transfer-messenger RNA (tmRNA) and its associated protein SmpB regulate the stability of RNase R. J. Biol. Chem. 285, 29054-29058. doi: 10.1074/jbc.C110.168641

Liang, W., Malhotra, A., and Deutscher, M. P. (2011). Acetylation regulates the stability of a bacterial protein: growth stage-dependent modification of RNase R. Mol. Cell 44, 160-166. doi: 10.1016/j.molcel.2011.06.037

Mao, C., Bhardwaj, K., Sharkady, S. M., Fish, R. I., Driscoll, T., Wower, J., et al. (2009) Variations on the tmRNA gene. RNA Biol. 6, 355-361. doi: 10.4161/rna.6.4.9172 Mehta, P., Richards, J., and Karzai, A. W. (2006). tmRNA determinants required for facilitating nonstop mRNA decay. RNA 12, 2187-2198. doi: 10.1261/rna.247706

Miller, M. R., and Buskirk, A. R. (2014). An unusual mechanism for EF-Tu activation during tmRNA-mediated ribosome rescue. RNA 20, 225-238. doi: 10.1261/rna.042226.113

Miller, M. R., Liu, Z., Cazier, D. J., Gebhard, G. M., Herron, S. R., Zaher, H. S., et al. (2011). The role of SmpB and the ribosomal decoding center in licensing tmRNA entry into stalled ribosomes. RNA 17, 1727-1736. doi: 10.1261/rna.2821711

Munavar, H., Zhou, Y., and Gottesman, S. (2005). Analysis of the Escherichia coli Alp phenotype: heat shock induction in ssrA mutants. J. Bacteriol. 187, 4739-4751. doi: 10.1128/JB.187.14.4739-4751.2005

Muto, A., Fujihara, A., Ito, K., Matsuno, J., Ushida C., and Himeno, H. (2000). Requirement of transfer-messenger RNA (tmRNA) for the growth of Bacillus subtilis under stresses. Genes Cells 5, 627-636. doi: 10.1046/j.1365-2443.2000.00356.x

Muto, A., Sato, M., Tadaki, T., Fukushima, M., Ushida, C., and Himeno, H. (1996). Structure and function of bacterial 10Sa RNA: trans-translation system. Biochimie 78, 985-991. doi: 10.1016/S0300-9084(97)86721-1 
Muto, A., Ushida, C., and Himeno, H. (1998). A bacterial RNA that functions as both a tRNA and an mRNA. Trends Biochem. Sci. 23, 25-29. doi: 10.1016/S09680004(97)01159-6

Muto, H., Nakatogawa, H., and Ito, K. (2006). Genetically encoded but nonpolypeptide prolyl-tRNA functions in the A site for SecM-mediated ribosomal stall. Mol. Cell 22, 545-552. doi: 10.1016/j.molcel.2006.03.033

Nameki, N., Tadaki, T., Muto, A., and Himeno, H. (1999a). Amino acid acceptor identity switch of Escherichia coli tmRNA from alanine to histidine in vitro. $J$ Mol. Biol. 289, 1-7. doi: 10.1006/jmbi.1999.2754

Nameki, N., Felden, B., Atkins, J. F., Gesteland, R. F., Himeno, H., and Muto, A. (1999b). Functional and structural analysis of a pseudoknot upstream of the tag-encoded sequence in E. coli tmRNA. J. Mol. Biol. 286, 733-744. doi: 10.1006/jmbi.1998.2487

Nameki, N., Chattopadhyay, P., Himeno, H., Muto, A., and Kawai, G. (1999c). An NMR and mutational analysis of an RNA pseudoknot of E. coli tmRNA involved in trans-translation. Nucleic Acids Res. 27, 3667-3675. doi: 10.1093/nar/27.18.3667

Nameki, N., Someya, T., Okano, S., Suemasa, R., Kimoto, M., Hanawa-Suetsugu, K., et al. (2005). Interaction analysis between tmRNA and SmpB from Thermus thermophilus. J. Biochem. 138, 729-739. doi: 10.1093/jb/mvi180

Nameki, N., Tadaki, T., Himeno, H., and Muto, A. (2000). Three of four pseudoknots in tmRNA are interchangeable and are substitutable with single-stranded RNAs. FEBS Lett. 470, 345-349. doi: 10.1016/S0014-5793(00)01349-1

Neubauer, C., Gillet, R., Kelly, A. C., and Ramakrishnan, V. (2012). Decoding in the absence of a codon by tmRNA and SmpB in the ribosome. Science 335, 1366-1369. doi: 10.1126/science.1217039

Nonin-Lecomte, S., Germain-Amiot, N., Gillet, R., Hallier, M., Ponchon, L., Dardel F., et al. (2009). Ribosome hijacking: a role for small protein B during transtranslation. EMBO Rep. 10, 160-165. doi: 10.1038/embor.2008.243

Oh, B. K., and Apirion, D. (1991). 10Sa RNA, a small stable RNA of Escherichia coli, is functional. Mol. Gen. Genet. 25, 737-749.

Okan, N. A., Bliska, J. B., and Karzai, A. W. (2006). A role for the SmpBSsrA system in Yersinia pseudotuberculosis pathogenesis. PLoS Pathog. 2:e6. doi: 10.1371/journal.ppat.0020006

Ono, K., Kutsukake, K., and Abo, T. (2009). Suppression by enhanced RpoE activity of the temperature-sensitive phenotype of a $\operatorname{deg} \mathrm{P}$ ssrA double mutant in Escherichia coli. Genes Genet. Syst. 84, 15-24. doi: 10.1266/ggs.84.15

Oussenko, I. A., Abe, T., Ujiie, H., Muto, A., and Bechhofer, D. H. (2005). Participation of $3^{\prime}$-to- $5^{\prime}$ exoribonucleases in the turnover of Bacillus subtilis mRNA. J. Bacteriol. 187, 2758-2767. doi: 10.1128/JB.187.8.2758-2767.2005

Palecková, P., Felsberg, J., Bobek, J., and Mikulík, K. (2007). tmRNA abundance in Streptomyces aureofaciens, S. griseus and S. collinus under stress-inducing conditions. Folia Microbiol. 52, 463-470. doi: 10.1007/BF02932105

Pech, M., Karim, Z., Yamamoto, H., Kitakawa, M., Qin, Y., and Nierhaus, K. H. (2011). Elongation factor 4 (EF4/LepA) accelerates protein synthesis at increased $\mathrm{Mg}^{2+}$ concentrations. Proc. Natl. Acad. Sci. U.S.A. 108, 3199-3203. doi: 10.1073/pnas.1012994108

Pedersen, K., Zavialov, A. V., Pavlov, M. Y., Elf, J., Gerdes, K., and Ehrenberg, M. (2003). The bacterial toxin RelE displays codon-specific cleavage of mRNAs in the ribosomal A site. Cell 112, 131-140. doi: 10.1016/S0092-8674(02)01248-5

Pisareva, V. P., Skabkin, M. A., Hellen, C. U., Pestova, T. V., and Pisarev, A. V. (2011). Dissociation by Pelota, Hbsl and ABCE1 of mammalian vacant $80 \mathrm{~S}$ ribosomes and stalled elongation complexes. EMBO J. 30, 1804-1817. doi: 10.1038/emboj.2011.93

Qi, H., Shimizu, Y., and Ueda, T. (2007). Ribosomal protein S1 is not essential for the trans-translation machinery. J. Mol. Biol. 368, 845-852. doi: 10.1016/j.jmb.2007.02.068

Ramadoss, N. S., Zhou, X., and Keiler, K. C. (2013a). tmRNA is essential in Shigella flexneri. PLoS ONE 8:e57537. doi: 10.1371/journal.pone.0057537

Ramadoss, N. S., Alumasa, J. N., Cheng, L., Wang, Y., Li, S., Chambers, B. S., et al. (2013b). Small molecule inhibitors of trans-translation have broadspectrum antibiotic activity. Proc. Natl. Acad. Sci. U.S.A. 110, 10282-10287. doi: 10.1073/pnas. 1302816110

Ramrath, D. J., Yamamoto, H., Rother, K., Wittek, D., Pech, M., Mielke, T., et al. (2012). The complex of tmRNA-SmpB and EF-G on translocating ribosomes. Nature 485, 526-529. doi: 10.1038/nature11006

Ranquet, C., and Gottesman, S. (2007). Translational regulation of the Escherichia coli stress factor RpoS: a role for SsrA and Lon. J. Bacteriol. 189, 4872-4879. doi: 10.1128/JB.01838-06
Rezzonico, E., Lariani, S., Barretto, C., Cuanoud, G., Giliberti, G., Delley, M., et al. (2007). Global transcriptome analysis of the heat shock response of Bifidobacterium longum. FEMS Microbiol. Lett. 271, 136-145. doi: 10.1111/j.15746968.2007.00704.x

Richards, J., Mehta, P., and Karzai, A. W. (2006). RNase R degrades non-stop mRNAs selectively in an SmpB-tmRNA-dependent manner. Mol. Microbiol. 62, 1700-1712. doi: 10.1111/j.1365-2958.2006.05472.x

Richter, R., Rorbach, J., Pajak, A., Smith, P. M., Wessels, H. J., Huynen, M. A., et al. (2010). A functional peptidyl-tRNA hydrolase, ICT1, has been recruited into the human mitochondrial ribosome. EMBO J. 29, 1116-1125. doi: 10.1038/emboj.2010.14

Roche, E. D., and Sauer, R. T. (1999). SsrA-mediated peptide tagging caused by rare codons and tRNA scarcity. EMBO J. 18, 4579-4589. doi: 10.1093/emboj/18.16.4579

Roche, E. D., and Sauer, R. T. (2001). Identification of endogenous SsrA-tagged proteins reveals tagging at positions corresponding to stop codons. J. Biol. Chem. 276, 28509-28515. doi: 10.1074/jbc.M103864200

Rudinger-Thirion, J., Giegé, R., and Felden, B. (1999). Aminoacylated tmRNA from Escherichia coli interacts with prokaryotic elongation factor Tu. RNA 5, 989-992. doi: 10.1017/S135583829999101X

Sharkady, S. M., and Williams, K. P. (2004). A third lineage with two-piece tmRNA. Nucleic Acids Res. 32, 1-8. doi: 10.1093/nar/gkh795

Shi, W., Zhang, X., Jiang, X., Yuan, H., Lee, J. S., Barry, C. E. III, et al. (2011). Pyrazinamide inhibits trans-translation in Mycobacterium tuberculosis. Science 333, 1630-1632. doi: 10.1126/science. 1208813

Shimizu, Y. (2012). ArfA recruits RF2 into stalled ribosomes. J. Mol. Biol. 423, 624-631. doi: 10.1016/j.jmb.2012.08.007

Shimizu, Y., and Ueda, T. (2002). The role of SmpB protein in trans-translation. FEBS Lett. 514, 74-77. doi: 10.1016/S0014-5793(02)02333-5

Shin, J.-H., and Price, C. W. (2007). The SsrA-SmpB ribosome rescue system is important for growth of Bacillus subtilis at low and high temperature. J. Bacteriol. 189, 3729-3737. doi: 10.1128/JB.00062-07

Singh, N. S., Ahmad, R., Sangeetha, R., and Varshney, U. (2008). Recycling of ribosomal complexes stalled at the step of elongation in Escherichia coli. J. Mol. Biol. 380, 451-464. doi: 10.1016/j.jmb.2008.05.033

Singh, N. S., and Varshney, U. (2004). A physiological connection between tmRNA and peptidyl-tRNA hydrolase functions in Escherichia coli. Nucleic Acids Res. 32, 6028-6037. doi: 10.1093/nar/gkh924

Shoemaker, C. J., Eyler, D. E., and Green, R. (2010). Dom34:Hbs1 promotes subunit dissociation and peptidyl-tRNA drop-off to initiate no-go decay. Science 330, 369-372. doi: 10.1126/science.1192430

Soma, A., Onodera, A., Sugahara, J., Kanai, A., Yachie, N., Tomita, M., et al. (2007). Permuted tRNA genes expressed via a circular RNA intermediate in Cyanidioschyzon merolae. Science 19, 450-453. doi: 10.1126/science.1145718

Someya, T., Nameki, N., Hosoi, H., Suzuki, S., Hatanaka, H., Fujii, M., et al. (2003). Solution structure of a tmRNA-binding protein, SmpB, from Thermus thermophilus. FEBS Lett. 535, 94-100. doi: 10.1016/S0014-5793(02)03880-2

Sunohara, T., Jojima, K., Yamamoto, Y., Inada, T., and Aiba, H. (2002). Nascentpeptide-mediated ribosome stalling at a stop codon induces mRNA cleavage resulting in nonstop mRNA that is recognized by tmRNA. RNA 10, 378-386. doi: $10.1261 /$ rna.5169404

Sunohara, T., Jojima, K., Yamamoto, Y., Inada, T., and Aiba, H. (2004a). Nascentpeptide-mediated ribosome stalling at a stop codon induces mRNA cleavage resulting in nonstop mRNA that is recognized by tmRNA. RNA 10, 378-386. doi: $10.1261 /$ rna.5169404

Sunohara, T., Jojima, K., Tagami, H., Inada, T., and Aiba, H. (2004b). Ribosome stalling during translation elongation induces cleavage of mRNA being translated in Escherichia coli. J. Biol. Chem. 279, 15368-15375. doi: 10.1074/jbc.M312805200

Tadaki, T., Fukushima, M., Ushida, C., Himeno, H., and Muto, A. (1996). Interaction of 10Sa RNA with ribosomes in Escherichia coli. FEBS Lett. 399, 223-226. doi: 10.1016/S0014-5793(96)01330-0

Takada, K., Takemoto, C., Kawazoe, M., Konno, T., Hanawa-Suetsugu, K., Lee, S., et al. (2007). In vitro trans-translation of Thermus thermophilus: ribosomal protein S1 is not required for the early stage of trans-translation. RNA 13, 503-510. doi: $10.1261 /$ rna.363207

Takahashi, T., Konno, T., Muto, A., and Himeno, H. (2003). Various effects of paromomycin on tmRNA-directed trans-translation. J. Biol. Chem. 278, 2767227680. doi: 10.1074/jbc.M211724200 
Thibonnier, M., Thiberge, J. M., and De Reuse, H. (2008). Trans-translation in Helicobacter pylori: essentiality of ribosome rescue and requirement of protein tagging for stress resistance and competence. PLOS ONE 3:e3810. doi: 10.1371/journal.pone.0003810

Tu, G. F., Reid, G. E., Zhang, J. G., Moritz, R. L., and Simpson, R. J. (1995). Cterminal extension of truncated recombinant proteins in Escherichia coli with a 10Sa RNA decapeptide. J. Biol. Chem. 270, 9322-9326. doi: 10.1074/jbc.270.16. 9322

Ude, S., Lassak, J., Starosta, A. L., Kraxenberger, T., Wilson, D. N., and Jung, K. (2013). Translation elongation factor EF-P alleviates ribosome stalling at polyproline stretches. Science 339, 82-85. doi: 10.1126/science. 1228985

Ueda, K., Yamamoto, Y., Ogawa, K., Abo, T., Inokuchi, H., and Aiba, H. (2002). Bacterial SsrA system plays a role in coping with unwanted translational readthrough caused by suppressor tRNAs. Genes Cells 7, 509-519. doi: 10.1046/j.1365-2443.2002.00537.x

Ujiie, H., Matsutani, T., Tomatsu, H., Fujihara, A., Ushida, C., Miwa, Y., et al. (2009). Trans-translation is involved in the CcpA-dependent tagging and degradation of TreP in Bacillus subtilis. J. Biochem. 145, 59-66. doi: 10.1093/jb/ mvn 143

Ushida, C., Himeno, H., Watanabe, T., and Muto, A. (1994). tRNA-like structures in 10Sa RNAs of Mycoplasma capricolum and Bacillus subtilis. Nucleic Acids Res. 22, 3392-3396. doi: 10.1093/nar/22.16.3392

Weis, F., Bron, P., Rolland, J. P., Thomas, D., Felden, B., and Gillet, R. (2010a). Accommodation of tmRNA-SmpB into stalled ribosomes: a cryo-EM study. RNA 16, 299-306. doi: 10.1261/rna.1757410

Weis, F., Bron, P., Giudice, E., Rolland, J. P., Thomas, D., Felden, B., et al. (2010b). tmRNA-SmpB: a journey to the centre of the bacterial ribosome. EMBO J. 29, 3810-3818. doi: 10.1038/emboj.2010.252

Williams, K. P. (2002). Descent of a split RNA. Nucleic Acids Res. 30, 2025-2030. doi: $10.1093 / \mathrm{nar} / 30.9 .2025$
Williams, K. P., Martindale, K. A., and Bartel, D. P. (1999). Resuming translation on tmRNA: a unique mode of determining a reading frame. EMBO J. 18, 5423-5433. doi: $10.1093 / \mathrm{emboj} / 18.19 .5423$

Wower, I. K., Zwieb, C., and Wower, J. (2004). Contributions of pseudoknots and protein SmpB to the structure and function of tmRNA in trans-translation. $J$. Biol. Chem. 279, 54202-54209. doi: 10.1074/jbc.M410488200

Wower, I. K., Zwieb, C. W., Guven, S. A., and Wower, J. (2000). Binding and cross-linking of tmRNA to ribosomal protein S1, on and off the Escherichia coli ribosome. EMBO J. 19, 6612-6621. doi: 10.1093/emboj/19.23.6612

Yamamoto, Y., Sunohara, T., Jojima, K., Inada, T., and Aiba, H. (2003). SsrAmediated trans-translation plays a role in mRNA quality control by facilitating degradation of truncated mRNAs. RNA 9, 408-418. doi: 10.1261/rna.2174803

Yanofsky, C. (2007). RNA-based regulation of genes of tryptophan synthesis and degradation, in bacteria. RNA 13, 1141-1154. doi: 10.1261/rna.620507

Conflict of Interest Statement: The authors declare that the research was conducted in the absence of any commercial or financial relationships that could be construed as a potential conflict of interest.

Received: 26 January 2014; accepted: 15 March 2014; published online: 07 April 2014. Citation: Himeno H, Kurita D and Muto A (2014) tmRNA-mediated trans-translation as the major ribosome rescue system in a bacterial cell. Front. Genet. 5:66. doi: 10.3389/ fgene.2014.00066

This article was submitted to Non-Coding RNA, a section of the journal Frontiers in Genetics.

Copyright (c) 2014 Himeno, Kurita and Muto. This is an open-access article distributed under the terms of the Creative Commons Attribution License (CC BY). The use, distribution or reproduction in other forums is permitted, provided the original author(s) or licensor are credited and that the original publication in this journal is cited, in accordance with accepted academic practice. No use, distribution or reproduction is permitted which does not comply with these terms. 